\title{
Avaliação de alunos e professores acerca do software "Sinais Vitais""*
}

\author{
EVALUATION OF STUDENTS AND TEACHERS CONCERNING \\ THE "VITAL SIGNS" SOFTWARE
} EVALUACIÓN DE ESTUDIANTES Y PROFESORES ACERCA DEL
SOFTWARE "SEÑALES VITALES"

\author{
Marcos Venícios de Oliveira Lopes ${ }^{1}$, Thelma Leite de Araujo ${ }^{2}$
}

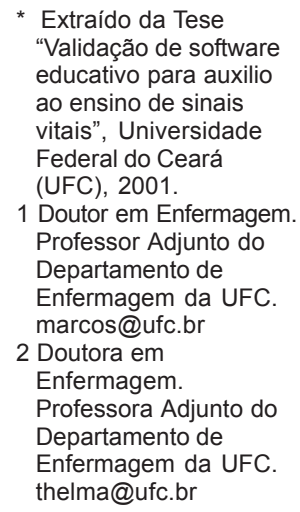

1 Doutor em Enfermagem. Professor Adjunto do Departamento de

Enfermagem da UFC. marcos@ufc.br

2 Doutora em

Enfermagem.

Professora Adjunto do

Departamento de

Enfermagem da UFC.

thelma@ufc.br

\begin{abstract}
RESUMO
Este artigo teve por objetivo levantar as opiniões de alunos e professores sobre o software "Sinais Vitais". O trabalho foi desenvolvido no Departamento de Enfermagem da Universidade Federal do Ceará. Trabalhou-se com um total de seis alunos e três professores, os quais foram submetidos a uma entrevista após a utilização do software. As entrevistas geraram dez categorias, as quais foram separadas em dois temas: Características que estimularam a utilização do software "Sinais Vitais" e Software educacionalmente correto. Concluiuse que os professores valorizaram a correção do conteúdo, enquanto os alunos enfocaram mais a dinâmica do programa.
\end{abstract}

\section{DESCRITORES}

Aplicação de informática médica.

Software.

Educação em enfermagem.

\begin{abstract}
This article had for objective to get students' and teacher's opinions about "Vital Signals" software. The investigation was developed in the Nursing Department of the Federal University of Ceará. The sample population was a total of 6 students and 3 teachers, who were submitted to an interview after using the software. The interviews generated 10 categories, which were separated in two themes: Features which stimulated the use of the "Vital Signals" software; and software educationally correct. The results showed that the teachers valued the correction of the content, while the students focused more on the dynamics of the program.
\end{abstract}

\section{DESCRIPTORS}

Medical informatics

application.

Software.

Nursing education.

\section{RESUMEN}

Este artículo tuvo por objetivo levantar las opiniones de alumnos y profesores sobre el software "Señales Vitales". El trabajo fue desarrollado en el Departamento de Enfermería de la Universidad Federal de Ceará. Se trabajó con un total de 6 alumnos y 3 profesores, los cuales fueron sometidos a una entrevista después de la utilización del software. Las entrevistas generaron 10 categorías, que fueron separadas en dos temas: Características que estimularon la utilización del software "Señales Vitales"; y software educativamente correcto. Se concluyó que los profesores valoraron la corrección del contenido, mientras que los alumnos enfocaron más la dinámica del programa.

\section{DESCRIPTORES}

Aplicaciones de informática médica.

Programas de computación.

Educación en enfermería. 


\section{INTRODUÇÃO}

A forma de encarar a educação evoluiu de acordo com a visão que dela se teve durante os anos. A maneira de conceber a aprendizagem determinava as estratégias, os recursos e os métodos de avaliação utilizados. Uma das primeiras correntes que pensou no uso de máquinas que mediassem o ensino foi a behaviorista, também conhecida como Teoria do Condicionamento.

O modelo do Condicionamento Operante de Skinner, considera a aprendizagem sob a óptica de que o comportamento humano poderia ser controlado. Esse autor fez grande sucesso no meio acadêmico durante as décadas de 60 e 70, chegando a defender o uso do que chamava máquinas de ensinar. Estas máquinas chegam, em alguns momentos, a lembrar o uso atual dos computadores no ensino, entretanto, a concepção do autor acerca da aprendizagem reduz as possibilidades de uma verdadeira "construção do conhecimento", considerando-se que os objetivos de tais máquinas eram produzir um comportamento, consolidando tais máquinas como um fim em si mesmas. Embora Skinner defendesse a presença do professor, afirmando que as máquinas de ensinar o libertariam das tarefas fatigantes para desenvolver seu papel de orientador, parece que suas idéias não floresceram de forma adequada, e sua aplicação acabou se desenvolvendo por uma vertente mecanicista ${ }^{(1-2)}$.

As correntes de aprendizagem mais recentemente discutidas incluem: a corrente do pensamento reflexivo, a aprendizagem baseada em problemas (PBL - Problem Based Learning) e a ciência cognitiva. A primeira corrente propõe que para o exercício da reflexão ativa é necessário conduzir o aluno a buscar a solução de um problema. $\mathrm{O}$ ato de pensar reflexivamente incute a idéia de necessitar da resposta. Entretanto, não existem receitas para a solução dos problemas, até porque estes são inesperados, e, acrescente-se, cada caso é um caso diferente com características próprias e que poderá necessitar de intervenções específicas. Isto nos levaria a uma lista infindável de etapas para resolver problemas $^{(3-5)}$.

A base filosófica em que se sustenta a PBL é a resolução de problemas, sendo o norte deste modelo, a consciência de que o aprendizado do ser humano se faz a partir de experi- ências do seu cotidiano. Além disso, os principais objetivos da PBL são desenvolver no estudante as habilidades de gerenciar o próprio aprendizado, de integrar o conhecimento, de identificar e explorar áreas novas ${ }^{(6)}$.

Com respeito à ciência cognitiva, seu principal objetivo é explicar como as pessoas chegam aos seus diferentes tipos de pensamento. A maioria dos cientistas cognitivos acredita que o conhecimento dentro da mente consiste em representações mentais, as quais podem ser encaradas por seis abordagens: a lógica, as regras, os conceitos, as imagens, as analogias e as conexões ${ }^{(7)}$.

Acreditamos que, como ferramenta de trabalho, o computador poderá seguir qualquer uma destas vertentes, dependendo da pessoa que o estará utilizando. As habilidades para trabalhar com esta nova ferramenta e a visão de educação do professor serão características que definirão o rumo a ser tomado. Melhor dizendo, aquele que domina plenamente e controla em última instância as máquinas, continua sendo o próprio homem ${ }^{(8)}$.

É comum encontrarmos resistência ao uso da informática porém, o medo associado aos progressos desta tecnologia, ainda se dá pela falta de informação/conhecimento. Em si, a informática sofreria dos mesmos medos que qualquer outro recurso tecnológico sofreu quando do seu surgimento. Sendo assim, a corrente radical contra os computadores tem seus adeptos entre os seguidores da educação formal, quase sempre impermeáveis às inovações $^{(9-10)}$.

A resistência a esta inovação no ensino não é algo restrito aos professores de escolas públicas ou mesmo escolas primárias. $\mathrm{Na}$ verdade, em nossa realidade, o pouco incentivo ao aperfeiçoamento dos docentes em termos salariais compatíveis com sua titulação e a dificuldade de liberação de verbas para o desenvolvimento de projetos, têm se mostrado como grandes empecilhos no despertar pela tecnologia do ensino. Isto se torna mais grave, quando falamos em universidades, já que estas deveriam ser sítios de construção do conhecimento. São ainda precárias as informações dominadas pelos educadores sobre as transformações pelas quais o ensino vem passando, sobretudo em virtude da utilização de tecnologias avançadas ${ }^{(11)}$.

O domínio destas novas habilidades pressupõe um esforço e uma dedicação profunda
Avaliação de alunos e professores acerca do software "Sinais Vitais" 
Marcos Venícios O. Lopes Thelma Leite de Araujo ao ensino e à atualização. $\mathrm{O}$ dinamismo e o estímulo à participação são requisitos bási$\cos$ de uma verdadeira interação professoraluno, caracterizando a construção coletiva do saber, rejeitando a didática vertical ultrapassada e há muito deixada de lado pela moderna educação ${ }^{(12)}$. Isto é demonstrado pelo crescente interesse na aplicação da informática na área de saúde, mais especificamente no desenvolvimento e avaliação de softwares educativos ${ }^{(13-15)}$.

Este processo participativo é tido como o envolvimento de sujeitos nas responsabilidades de execução, elaboração e avaliação, que possibilita a formação crítica dos profissionais, estimulando a construção de projetos pessoais e a tomada de iniciativas tão exigidas atualmente ${ }^{(16)}$.

Um modelo utilizado para avaliação de softwares para uso no ensino, que vem sendo difundido no Brasil, é o Modelo de Apreciação Analítica de Sistemas Hipermídia. Nele, o enfoque baseia-se na observação, análise e julgamento como estratégia para o planejamento, produção e seleção de materiais educacionais. $\mathrm{O}$ modelo representa uma vertente que defende a aprendizagem como um processo cognitivo complexo que recebe influências de fatores diversos, não podendo considerar este recurso como um fim em si mesmo $^{(17)}$.

Os procedimentos utilizados para este tipo de avaliação incluem a utilização do material por sujeitos que, de alguma forma, possuem vinculação com seu conteúdo, a avaliação dos materiais por meio de questionários/entrevistas e a formação de painéis para discussão. Os participantes do estudo incluem representantes do grupo de alunos e professores/ especialistas no tópico do programa.

O Modelo de Apreciação Analítica de Sistemas Hipermídia é de grande relevância para análise de softwares utilizados no ensino de enfermagem, tendo em vista alguns aspectos importantes: possibilita a participação ativa do aluno; trabalha a interação professor-aluno como etapa importante na construção de recursos pedagógicos; considera a aprendizagem sob o ponto de vista cognitivo, entendendo-a como reflexo de fatores diversos; e prevê uma oportunidade para o desenvolvimento de uma plataforma de alta interatividade, maximizando a possibilidade de aprendizagem do tópico estudado.
Com base nisto, o presente artigo objetivou levantar as opiniões de alunos e professores do Curso de Graduação em Enfermagem sobre o software "Sinais Vitais", visando contribuir com o ensino nesta área do conhecimento de enfermagem.

\section{MATERIALE MÉTODO}

O estudo é baseado na avaliação de um software educativo, objetivando sua utilização em disciplinas que enfocam o conteúdo curricular relativo à avaliação de sinais vitais. Teve como base uma experiência efetuada junto a professores e alunos que trabalham o referido tema, mediante uma abordagem participativa, na qual buscamos uma avaliação de cunho qualitativo baseada no Modelo de Apreciação Analítica de Sistemas Hipermídia ${ }^{(17)}$.

A pesquisa partiu do desenvolvimento prévio do software "Sinais Vitais", desenvolvido na plataforma Toolbook II Instructor 6.1 a da Asimetrix Corporation. O trabalho de programação foi realizado por um dos autores do estudo. O software educativo construído é caracterizado como ramificado, por permitir ao aluno saltar tópicos, retornar ou avançar gradativamente no tema, de acordo com sua necessidade e interesse. O software está composto por textos, palavraschave, vídeos, animações, figuras, fotos e sons, caracterizando uma instrução hipermídia. O tema aborda os tópicos relativos à avaliação de sinais vitais, conforme o conteúdo do programa da disciplina Semiologia, da instituição onde foi realizada a pesquisa. Tais tópicos foram desenvolvidos tendo como base na literatura pertinente.

Os tópicos do software estão divididos em itens, cada um deles enfocando um aspecto relevante do tema a ser estudado. É permitido ao usuário saltar, tanto de um tópico para outro como de um item para outro, através de links estabelecidos entre tópicos comuns a partir da relação conceitual entre eles, e podem ser divididos em dois tipos: os internos, nos quais a informação surge ao se colocar o mouse sobre o item, e os externos, que surgem após se clicar sobre o item, levando o usuário a outro setor do programa. Para facilitar a navegabilidade, os links são destacados com uma cor diferente do restante do texto. A seguir, citamos os tópicos abordados no software:Avaliação do Pulso; Ava- 
liação da Pressão Arterial; Avaliação da Respiração; Avaliação da Temperatura Corporal.

Além deles, o software conta com outras oito funções de apoio ao aprendizado: um setor com os diagnósticos de enfermagem relacionados à avaliação de sinais vitais; um setor com um estudo de caso; um glossário com termos técnicos para consulta; um teste de conhecimentos; um histórico contendo o registro dos itens já consultados pelo usuário; um mapa de conteúdo com uma representação gráfica dos tópicos a serem estudados e onde o usuário pode saltar imediatamente para qualquer ponto do conteúdo; uma busca que permite ao usuário procurar uma palavra, tópico ou frase em todo o programa; e um jogo dos erros, onde o usuário deve identificar, em diversas fotos, erros na execução de técnicas da avaliação de sinais vitais. Os tópicos do conteúdo seguem uma estrutura semelhante, que inclui os seguintes pontos: Locais de verificação, Fatores que influenciam, Pontos a serem avaliados e Semiotécnica. Alguns tópicos apresentam mais pontos em razão das características a eles intrínsecos.

A população foi constituída por todos os alunos e professores da disciplina de Semiologia do Curso de Enfermagem da Faculdade de Farmácia, Odontologia e Enfermagem da Universidade Federal do Ceará. A amostra constou dos professores e alunos que atendiam aos seguintes critérios: aceitação voluntária para participação no estudo conforme termo de consentimento; ser professor da disciplina ou aluno regularmente matriculado na mesma; ter conhecimentos básicos de informática.

Para os professores, foram determinados como critérios de exclusão o conhecimento prévio e a participação na elaboração do software, o que eliminou o professor que é autor deste trabalho. Participaram do estudo seis alunos e três professores que se disponibilizaram voluntariamente após consulta ao grupo docente e discente da disciplina. Os alunos não haviam tido contato anterior com o tema sinais vitais.

Os dados foram coletados a partir de entrevistas com a amostra definida ocorridas nos meses de março a abril de 2001. Cada um dos participantes do estudo (professores e alunos) recebeu uma cópia do software para ser avaliado. A análise dos professores re- caiu sobre o conteúdo, a linguagem utilizada e a forma como o tema foi abordado. Aos alunos, coube a avaliação do envolvimento cognitivo e afetivo, clareza e facilidade da aprendizagem, comunicação com o programa, motivação, liberdade de ação e interatividade. Os professores e alunos são aqui identificados pelas letras $\mathrm{P}$ e A respectivamente, seguidos de um número seqüencial.

Cada professor trabalhou de forma independente, definindo o local e horário compatível com sua disponibilidade. Eles foram entrevistados, individualmente, após a utilização e avaliação do software. As entrevistas com os alunos também foram individuais, e se realizaram logo após a utilização do programa na sala de informática da Faculdade de Medicina da Universidade Federal do Ceará. As entrevistas aconteceram em ambiente privado seguindo roteiro pré-estabelecido. Tal roteiro foi desenvolvido com base no Modelo de Apreciação Analítica de Sistemas Hipermídia, levando-se em consideração as recomendações sobre avaliação de títulos educacionais em multimídia ${ }^{(17-18)}$. Os relatos foram gravados em fita cassete após solicitação formal.

Os dados foram organizados em categorias e analisados pela técnica de análise de conteúdo, a qual incluiu três momentos ${ }^{(19)}$ :

- Pré-análise - a partir do material coletado nas falas dos entrevistados e nos formulários, foram elaborados os indicadores de avaliação que orientaram a interpretação final do trabalho. Nesta fase, foram efetuadas leituras exaustivas, visando à familiarização com o material e à sua organização, estabelecendo algumas normas de validade, como representatividade, homogeneidade e pertinência.

- Exploração do material - consistiu na codificação, agregação e escolha das categorias teóricas.

- Interpretação dos resultados - procuramos os significados das categorias estabelecidas. Para isto, foi utilizada a literatura pertinente ao processo educativo cognitivo e nas idéias básicas da corrente educacional do pensamento reflexivo ${ }^{(3-5,7)}$.

O trabalho foi submetido à apreciação do Comitê de Ética e Pesquisa da Universidade Federal do Ceará e foi solicitada a permissão para divulgação dos dados da pesquisa por
Avaliação de alunos e professores acerca do software "Sinais Vitais" 
Marcos Venícios O. Lopes Thelma Leite de Araujo meio da assinatura do termo de consentimento, segundo modelo utilizado pelo referido Comitê.

\section{DISCUSSÃO}

Em seguida à leitura e análise das entrevistas, encontramos 10 categorias que emergiram das falas, as quais foram separadas em dois temas. O primeiro tema, Características que estimulam a utilização do software "Sinais Vitais", abrange as categorias que tratam das características do software que estimularam os usuários a utilizarem-no como instrumento de ensino-aprendizagem. Incluiu as seguintes categorias:

a) Boa navegabilidade;

b) Distribuição adequada do conteúdo;

c) Linguagem fácil;

d) Motivação, e

e) Liberdade de ação.

O segundo tema, Software educacionalmente correto, incluiu:

a) Recurso complementar ao ensino;

b) Uso adequado de mídias;

c) Conteúdo adequado;

d) Adequação ao tema.

\section{Tema 1 - Características que estimulam a utilização do software "Sinais Vitais"}

Neste primeiro tema, são descritas cinco categorias que caracterizam o software "Sinais Vitais" como motivador.

\section{a) Boa Navegabilidade}

A boa navegabilidade é a característica que permite ao usuário "andar" pelo programa de forma livre, facilitando ao máximo a busca de informações. A organização das ligações dos tópicos que compunham o software "Sinais Vitais" se estabelece sob a forma de redes, as quais favorecem o aprendizado. Nas falas seguintes, temos alguns exemplos de como alunos e professores perceberam a característica de navegabilidade do software em questão.

O que eu usei mais foi o histórico e... o mapa! Usei também o glossário; usei muito da outra vez. Eu achei que eles são indispensáveis porque se eu chego num determinado local e tem uma palavra que eu não sei... que eu procurei no glossário tinha! O mapa porque, pra mim não ficar saltando de tela em tela, eu ia lá no mapa, tinha o que eu queria e pronto! $\mathrm{E}$ o histórico foi muito importante nas pescadinhas! (A5)

Aquelas faixas vermelhas, a opção de voltar, ajuda demais aquilo ali. Às vezes a gente não lembra o que é, vai lá e olha achei bem interessante. Achei fácil de usar, assim uma coisa bem prática. Gostei que você colocou os tópicos todos assim: fatores, semiologia ... tudo assim. Acho melhor assim porque vai direto ao ponto, não precisa ficar procurando em todo o programa. (A4)

Eu acho assim, quando você fecha uma janela, por exemplo: pulso, aí você fecha tudo e não volta mais. Quando você tá vendo PA, temperatura aí você fecha tudo e abre a janelinha de pulso. Quando você colocou na PA todas as regrinhas de como você faz a medida, aí você repetiu depois iguaiszinhos os passos. Eu acho que fica bom por isso. $\mathrm{O}$ aluno fica voltando e ele vê que a seqüência é a mesma. Tem uma hora lá que você diz 'Ah, eu já vi isso antes' mas como você tem que ter essa seqüência, não dá pra ficar voltando porque atrapalharia pra quem tá usando. Eu achei importante tá repetido. (P2)

Nas falas, encontramos elementos que descrevem a forma como os sujeitos da pesquisa faziam sua busca de informações. É interessante ressaltar que essa foi a característica mais explorada pelos alunos do que pelos professores. Isto talvez esteja associado ao fato de que os alunos têm um hábito maior de acesso a documentos eletrônicos. Os pontos levantados que mais facilitaram a navegabilidade incluíram: o uso do histórico, do glossário, do mapa, das hotwords e dos viewers.

O histórico e o mapa de conteúdo foram desenvolvidos com o objetivo de facilitar a busca de páginas dentro do programa e sua função parece ter sido bem utilizada. O glossário foi idealizado como forma de auxiliar o indivíduo a entender termos científicos que possivelmente não seriam compreendidos por estudantes em seu primeiro contato com uma disciplina técnica. Sua função parece ter sido estendida para auxiliar não apenas na compreensão do termo, mas também de toda informação que se baseava naquele termo.

As hotwords eram pequenas ligações com informações explicativas ou mais 
aprofundadas sobre um tema em questão. O usuário não saía da página onde estava, mas podia ter acesso a outras janelas (viewers) onde visualizava textos, figuras e/ou fotos que complementavam a informação anteriormente repassada. $\mathrm{O}$ que não esperávamos era que os viewers em si (janelas independentes) pudessem ter sido encaradas como forma de navegabilidade, já que sua função foi pensada apenas como complemento das informações. Entretanto, um professor afirmou que a repetição de quadros ajudava o aluno a fixar o conteúdo e minimizava o tempo gasto para resgatar determinada informação.

Este tipo de afirmação relaciona-se com o conceito de redes conexionistas ${ }^{(7)}$ quando anota que a ativação de uma unidade (em nosso caso, a informação) pode ser interpretada como um julgamento sobre a aplicabilidade de um conceito ou a verdade de uma proposição. E as ligações entre essas unidades podem se dar diretamente, ou seja, de uma determinada informação para sua explicação, ou simétrica, quando a informação e a explicação se complementam mutuamente.

\section{b) Distribuição adequada do conteúdo}

Esta segunda categoria tem forte relação com a primeira, pelo fato de que a navegação pelo conteúdo apresentado é diretamente influenciada pela forma como o conteúdo está distribuído. Vale ressaltar que optamos por dividir as informações em tópicos e sub-tópicos, e em cada um deles havia informações que podiam ser resgatadas, mudando de página pelos instrumentos de navegabilidade, abrindo uma janela independente ou simplesmente parando o mouse sobre um ponto destacado. A seguir, temos as falas que descrevem a avaliação dos usuários sobre esta característica do software.

\footnotetext{
A interrelação dos tópicos foi boa. Quando a gente vê a questão do pulso, tem lá a freqüência cardíaca. Porque quando você abre o mapa, você vê logo tudo,dá pra perceber. (A2)

Eu acho que estava muito bem dividido, fácil de entender pela divisão porque com a divisão é muito mais fácil você aprender do que quando você pega um livro e é um parágrafo único, aquela coisa de ponta à cabeça, começo e final, com divisão é muito mais fácil. (A5)
}

Os alunos sentiram melhor do que os professores esta característica. A utilização freqüente de livros pelos estudantes tem deixado muitas lacunas no seu aprendizado. O livro congrega grande volume de informações e é um instrumento importante de consulta, entretanto, por sua característica linear, traz informações num formato unidirecional, tornando cansativa sua leitura e restringido a idéia de interrelação dos tópicos.

A necessidade de propiciar ao estudante uma visão relacional contribui para a resolução de problemas não instrumentais, ou seja, problemas que transcendem a racionalidade técnica e exigem a busca de soluções opcionais $^{(5)}$. Tais soluções para serem encontradas necessitam de um conhecimento global do problema. Assim, o aluno sente a necessidade de verificar as relações conceituais e a melhor forma é apresentar tais conceitos distribuídos de forma a se possibilitar o seu resgate com rapidez e precisão.

\section{c) Linguagem fácil}

A categoria "Linguagem fácil" apresenta os relatos de professores e alunos ao avaliarem a forma pela qual a informação textual foi repassada. A maior parte dos usuários fez referência a esta característica, entretanto, os professores a avaliaram com maior precisão do que os alunos. A seguir, temos três relatos que descrevem a avaliação da linguagem utilizada no software.

\begin{abstract}
Eu achei a linguagem bastante acessível. O que não tá tão acessível ao aluno acredito que é por alguma deficiência no conteúdo dele mesmo de anatomia ou de fisiologia, mas mesmo assim o glossário, você teve a preocupação de colocar um glossário, já auxilia muito o aluno. Se é o primeiro momento que a pessoa tá entrando em contato com aquele assunto então, tem essa facilidade de termos técnico-científicos, mas a redação em si eu achei bastante acessível, ao meu ver não traz nem uma complicação pra pessoa que tá usando. (P1)

A linguagem, eu gostei! Ela é assim o básico, conceitual, conceito de tudo. Então tem o primordial do que a gente precisa saber. É bom porque é prático, e aluno adora coisas práticas. (A6)
\end{abstract}

A linguagem é, por si, uma característica inerente ao ser humano. Sua adequada utilização determina a compreensão exata daqui-
Avaliação de alunos e professores acerca do software "Sinais Vitais" 
Marcos Venícios O. Lopes Thelma Leite de Araujo lo que se deseja repassar. $\mathrm{Na}$ avaliação dos usuários, além do uso de uma linguagem básica, foi ressaltada a existência de uma função que auxiliava a compreensão de termos científicos: o glossário. De fato, pelo menos três aspectos do uso da linguagem são de grande relevância: habilidade para compreendê-la, a habilidade para produzir expressões verbais e a capacidade de aprender a linguagem ${ }^{(7)}$.

Nisso, o repasse de informações ao se utilizar o software "Sinais Vitais" está diretamente ligado ao descrito anteriormente, entretanto, vale ressaltar que, quando a informação é repassada, uma das formas de confirmar sua exata compreensão é o modo pelo qual o aluno irá exteriorizá-la. Esta exteriorização pode ser verificada quando o estudante tenta resolver os exercícios propostos no próprio software.

\section{d) Motivação}

A motivação é uma característica que produz um estímulo direto para se desenvolver determinada ação. No software em questão, a temática da motivação foi exteriorizada apenas pelos professores. Os alunos, embora tenham demonstrado interesse relatando a necessidade de utilizar o programa mais vezes, não incluíram, nos seus depoimentos, esta característica. Os relatos a seguir mostram o despertar dos professores pela congregação de recursos multimídia que o software apresentava e que, para eles, se configurava como fator motivador para o aluno.

Eu acho que é uma coisa que motiva o aluno. Motiva até passar para a próxima unidade. É uma coisa que estimula; é diferente de um livro-texto que tem as informações semelhantes, mas que, para o aluno, nem sempre é tão motivante, apesar de alguns serem imaturos, principalmente nessa área. (P1)

Primeiro, eu achei interessante e atrativo, uma coisa inovadora. Eu acho que ele tem esse aspecto extremamente importante no sentido pedagógico. Ele é inovador, atrativo principalmente pro nosso aluno que é jovem e que nessa era, a informática é uma coisa muito própria dele. É muito mais uma propriedade do nosso aluno do que de um professor como eu que já tem muito tempo de ensino. Então, eu acho que isso chama mais a atenção. Torna mais interessante. (P3)
A motivação defendida pelos professores é o ícone que permite estimular o usuário a continuar utilizando o software. Esta utilização culmina com a tentativa de apreender as informações para resolver os exercícios nele propostos, que são: o teste de conhecimentos, o jogo dos erros e o estudo de caso.

Vale ressaltar que, embora os alunos não tenham relatado diretamente a característica de motivação, a descrição de outros pontos durante as entrevistas nos fez crer que esta esteve presente durante a utilização do software. Esta motivação se reflete no desafio lançado pelo programa de identificar erros de técnica e de formular um diagnóstico de enfermagem com base na avaliação de sinais vitais.

\section{e) Liberdade de ação}

Nesta última categoria do primeiro tema, é ressaltada a liberdade sentida pelos alunos ao interagirem com o software. Esta liberdade foi uma característica que se evidenciou, particularmente pelos alunos, e se apresenta como a possibilidade de poder "andar" pelo conteúdo e pelos exercícios de acordo com a própria vontade. Podemos perceber esta categoria nos relatos dos sujeitos A4 e A5.

Às vezes os professores na sala de aula esquecem de alguns tópicos porque se esquece mesmo, e ali tava tudo bem arrumadinho, todas as características e tudo. Eu sou muito assim: se eu to lá na frente e não me lembro aí eu volto, porque numa sala de aula eu não vou dizer "professora, volta aí, me explica de novo o que é isso." não! Eu chego em casa e vejo o que eu lembro. No computador não, eu imediatamente voltava para ver aquilo que eu não me lembrava mais e seguia adiante. (A5)

Aquele programa lá que faz a gente colocar a sistólica e a diastólica ... no estudo de caso você pode voltar, podia compartilhar, podia voltar, reler, tentar. Eu fui pra lá porque eu queria ajudar, pra saber se ajuda, se ajuda mais ou se é a mesma coisa de quem não foi né?! Eu queria aprender mais. Acho que aprendi. Eu tive essa facilidade de ir, de ganhar tempo, vejo mais coisas em menos tempo. (A4)

A possibilidade de escolher o próprio caminho e o seguir conforme sua expectativa e necessidade caracteriza a liberdade de ação no software "Sinais Vitais". Esta liberdade permite o aprendizado diferenciado e no ritmo de cada aluno, mesmo que o professor 
esteja trabalhando com vários ao mesmo tempo.

A heterogeneidade é uma característica própria do ser humano, pois cada pessoa apresenta características e expectativas peculiares, não cabendo a uniformização como estratégia de ensino. A dificuldade de gerenciar a sala de aula é um desafio esperado e, inclusive, já relatado em estudos que avaliaram a utilização de computadores em sala de aula ${ }^{(20)}$.

\section{Tema 2 - Software educacionalmente correto}

Neste segundo tema, descrevemos as categorias que serviram para definir as características didáticas do software "Sinais Vitais".

\section{a) Recurso complementar ao ensino}

Uma das características esperadas quando utilizamos computadores em nosso dia-adia, é que eles nos sirvam de auxiliares na execução de tarefas, maximizando a qualidade do produto final e otimizando o tempo gasto. Em nosso estudo, o software "Sinais Vitais" foi freqüentemente apontado como complemento ao trabalho em sala de aula. Vejamos:

\begin{abstract}
Eu acho que depois da aula. Primeiro uma teórica (aula), mesmo porque por mais que você coloque aí ... tem bastante detalhes, mas na aula você dialoga com o aluno, ele faz as questões porque aí ele tá mudo com o computador. Então acho que a aula abre a visão pra ele absorver essas informações a posteriori. (P2)
\end{abstract}

Em relação aos alunos que tiveram em sala de aula, a gente que tinha participado da pesquisa, estava mais seguro com as informações que tínhamos. Foi dado em sala de aula, mas quando a gente tinha visto, constatado coisas que não foram dadas até pelo tempo, mas que, com o programa tinha como a gente fixar aquilo, que você tá vendo, que você tá utilizando o programa, que você tá verificando como aquilo funciona, é mais fácil de assimilar do que você ir ao livro. (A3)

A maior parte dos relatos desta categoria foi de professores, embora alguns alunos também o tenham feito. É fato que os professores se detiveram muito no conteúdo apresentado, e, consequentemente, também se preocuparam em como utilizar aquele software. Os alunos, ao contrário, se preocu- param em utilizar o software e em observar a facilidade de seu manuseio.

O reforço ao que se procura ensinar é uma forma de incrementar relações conceituais e técnicas. O software "Sinais Vitais", de fato, apresenta várias formas de reforço, as quais ultrapassam a mera repetição do conteúdo. Além da apresentação de conceitos, a utilização de imagens visuais e sonoras, bem como o uso de conexões entre as páginas, são características que se relacionam às abordagens da ciência cognitiva ${ }^{(7)}$.

\section{b) Uso adequado de mídias}

A utilização de mídias em softwares educativos é uma constante. Sua presença atua como elemento de imagem que fortalece a compreensão de um conteúdo. Nos relatos a seguir, professores e alunos defendem a coerência entre as diversas mídias apresentadas:

\begin{abstract}
Aquela parte de pressão arterial a gente tinha de auscultar os sons. Os vários tipos de sons, que acontecem no pulmão. Você tem a necessidade de verificar sem ter necessariamente uma pessoa para verificar. Através dali, além de você tá lendo sobre aquele tipo de som você tá constatando através do som. (A3)
\end{abstract}

\begin{abstract}
No conteúdo de respiração o que me chamou mais a atenção, e eu achei fantástico, foram as figurinhas. Dá até pra visualizar bem aquela animação de respiração torácica, tóraco-abdominal, porque eles têm muita dificuldade de verem na prática, apesar da gente falar: no recémnascido, imaginem uma criança ... mas quando eles vão ver na prática muitas vezes têm dificuldade, e eu achei que com aquela animação eles visualizam melhor. Não fica só na imaginação. (P1)
\end{abstract}

Ao analisarmos esta categoria sob o prisma da ciência cognitiva, poderíamos dizer que as mídias se apresentam como imagens. Embora muitos cientistas cognitivos tenham se prendido às imagens como representações visuais, é importante não ignorar as imagens não visuais ${ }^{(7)}$. Em nosso caso, grande parte das imagens apresentadas foi visual, apenas os sons se caracterizaram como imagens não visuais.

As imagens visuais têm forte poder de representação, levando-se em conta que, mesmo após encerrado o contato com elas, ainda somos capazes de formar uma repre-
Avaliação de alunos e professores acerca do software "Sinais Vitais" 
Marcos Venícios O. Lopes Thelma Leite de Araujo sentação. Esta possibilidade é exteriorizada pelo professor P1, que defende a melhoria da compreensão dos movimentos respiratórios quando estes são mostrados sob a forma de animação.

\section{c) Conteúdo adequado}

Esta categoria tem características distintas da "Distribuição adequada do conteúdo" pelo fato de que, nesta, abordamos a forma como o conteúdo está dividido e suas interrelações.

O conteúdo eu gostei... Eu estudei agora para a prova de temperatura e o conteúdo tava bem relacionado ao que tava lá e os outros eu achei também assim o básico, o suficiente. Eu não acho que ele deva ser ampliado não. Se pudesse sintetizar tudo bem, mas separado é bom pra ver. (A1)

Pra mim, no meu entender, dentro do que eu já vi durante esses anos do que a gente ensina em relação a sinais vitais, eu acho que ele não deixa nada a desejar. Inclusive eu acho que ele tem uma forma assim, mais direta, mais simples de atingir alguns conceitos, de forma que eu achei muito interessante. Ele foge daqueles conceitos muito trabalhados que no final termina o aluno perdendo a essência da coisa. Ele vai direto. Eu achei muito interessante. (P3)

Estes relatos são pertinentes ao que se chama aplicabilidade prática, ou seja, um critério de avaliação das representações mentais onde se busca aumentar a compreensão de como os estudantes aprendem e de sugerir como ensiná-los melhor. A aplicabilidade prática é o critério que pode ser utilizado para planejar interfaces agradáveis em programas de computador ${ }^{(7)}$.

Acreditamos que a aplicabilidade prática deva conduzir ao desenvolvimento de softwares educativos otimizados em suas diversas características. A adequação do conteúdo é uma dessas características que despertam o interesse do usuário que busca informações rápidas e precisas. O professor P3 mostrou que o conteúdo foi apresentado de forma direta e simples, e o aluno A1 defendeu a boa associação entre o que foi apresentado no software e o que foi exigido deles como estudantes na disciplina Semiologia.

\section{d) Adequação ao tema}

A adequação ao tema é uma característica que deve, necessariamente, estar presente nos softwares educativos. Isto porque a pertinência destes depende da necessidade e da possibilidade de aplicação do programa.

Olha, eu achei que pra assuntos bastante simples e que a ilustração enriquece bastante, o programa é $100 \%$. Agora se fosse um tema mais extenso que teria que ter um conhecimento mais detalhado pra compreender uma patologia, aí eu acho que o programa fica inadequado. Não é nem o programa em si, é o próprio uso do computador. Eu acho que no livro você se debruça mais, tem condição de buscar outras informações. Mas, para temas sucintos em que a ilustração enriquece bastante, como é o caso de sinais vitais, ele fica bem mais atraente que o livro, e pode ser mais interativo para o aluno. (P2)

O conteúdo eu achei bastante pertinente. Primeiro o conteúdo com o uso do computador, casou perfeitamente. Não sei se pra outros conteúdos seria bom. Mas pra esse, sinais vitais, inclusive por ser sucinto, um programa que o aluno vai ter a prática, de fato ele norteia bem o que ele tem que ver, os pontos chaves e depois na prática reforça bastante esse conteúdo. (P2)

Esta categoria foi defendida pelo professor P2, com a justificativa de que a adequação do software se relacionou ao fato de este ter um conteúdo sucinto. Concordamos que seja sucinto, quando comparado com outros assuntos, entretanto, o formato deste software pode ter contribuído para que se acredite, erroneamente, que todos os softwares educativos tenham que ter sempre o mesmo formato.

$\mathrm{Na}$ verdade, qualquer aplicativo pode ter sua vertente educacional. Nesse ponto acreditamos que um software educativo deve ser classificado de acordo com o uso que se faz dele ${ }^{(21)}$. Assim, para a temática "Sinais Vitais", este software parece estar adequado a ser utilizado como um recurso complementar, conforme defendido anteriormente por alunos e professores. 


\section{CONCLUSÕES E CONSIDERAÇÕES FINAIS}

Percebemos que, além de deter características essenciais que contribuem de forma efetiva para o aprendizado dos estudantes de graduação, a avaliação do software "Sinais Vitais" mostrou que os professores valorizaram a correção do conteúdo, enquanto os alunos buscaram a melhor dinâmica para $o$ programa.
A partir das considerações aqui apresentadas, acreditamos serem necessárias a constante revisão do programa, bem como a criação de outros que possam auxiliar o professor na formação de enfermeiros. O software educativo não substitui outras fontes de consulta, mas sua dinâmica provê ao aluno maior agilidade na busca de informações que sirvam ao seu aprendizado. A rapidez de acesso se reflete no ganho de tempo e na possibilidade de aprofundamento por meio de outras fontes de consulta.

\section{REFERÊNCIAS}

(1) Skinner BF. Tecnologia do ensino. São Paulo: EPU; 1972.

(2) Skinner BF. Ciência e comportamento humano. São Paulo: Martins Fontes; 1981.

(3) Dewey J. Como pensamos. São Paulo: Editora Nacional; 1959.

(4) Polya G. A arte de resolver problemas: um novo aspecto do método matemático. Rio de Janeiro: Interciência; 1978.

(5) Schön D. Educando o profissional reflexivo: um novo design para o ensino e a aprendizagem. Porto Alegre: Artes Médicas Sul; 2000.

(6) Rodrigues MLV, Figueiredo JFC. Aprendizado centrado em problemas. In: Anais do $1^{\circ}$ Simpósio Ensino Médico de Graduação; 1996 out; Ribeirão Preto. Ribeirão Preto: USP; 1996. p. 396-402.

(7) Thagard P. Mente: introdução à ciência cognitiva. Porto Alegre: Artmed; 1998.

(8) Saviani D. O trabalho como princípio educativo frente às novas tecnologias. In: Ferretti CJ. Novas tecnologias, trabalho e educação: um debate multidisciplinar. $3^{a}$ ed. Petrópolis: Vozes; 1994. p. 151-68.

(9) Fasciani R. Novas tecnologias informáticas, mass media e relações afetivas. In: Peluso A, organizador. Informática e afetividade. Bauru: EDUSP; 1998. p.119-34.

(10) Niskier A. Tecnologia educacional: uma visão política. Petrópolis: Vozes; 1993.

(11) Ferretti CJ, Zibas DML, Madeira FR, Franco MLPB. Novas tecnologias, trabalho e educação: um debate multidisciplinar. $3^{\mathrm{a}}$ ed. Petrópolis: Vozes; 1994.
(12) Lopes MVO, Araujo TL, Borges Neto H. A informática e as correntes pedagógicas na enfermagem. Rev Rene 2001; 2(2):52-8.

(13) Lopes MVO, Araujo TL. Processo de informatização em saúde: temas abordados em artigos publicados no período de 1978 a 1998. Rev Esc Enferm USP 2002; 36(1): 25-32.

(14) Lopes MVO, Araujo TL. Validação do software "Sinais vitais" por um painel de especialistas. Rev Paul Enferm 2003 maio ago; 22(2):166-74.

(15) Lopes MVO, Silva VM, Araujo TL. Desenvolvimento lógico-matemático do software ND. Rev Lat Am Enferm 2004; 12(1):92100 .

(16) Lunardi VL, Borba MR. O pensar e o fazer da prática pedagógica: a busca de uma nova enfermeira. In: Saupe R, organizador. Educação em enfermagem. Florianópolis: Ed. UFSC; 1998. p. $163-86$

(17) Struchinner M, Côrrea N, Costa JBS. Hipermídia na educação: princípios básicos para o desenvolvimento de material educativo. Rio de Janeiro: NUTES/UFRJ; 1997.

(18) Reeves TC. Evaluating interactive multimedia. Educ Technology 1992; 32(5):47-53.

(19) Bardin L. Análise de conteúdo. Lisboa: Edições 70; 1979.

(20) Sandholtz JH, Ringstaff C, Dwyer D. Ensinando com tecnologia: criando salas de aula centrada nos alunos. Porto Alegre: Artes Médicas; 1997.

(21) Borges Neto H. Uma classificação sobre a utilização do computador pela escola. Educ Deb 1999; 1(37):135-8.
Avaliação de alunos e professores acerca do software "Sinais Vitais"
Correspondência para: Marcos Venícios O. Lopes Rua Almirante Rubim, 804 Montese - Fortaleza CEP - 60925-480 - CE 